\title{
VITAMIN-RESISTANT RICKETS
}

BY

A. MORTON GILL, M.D., M.R.C.P.

(From the Children's Department, Middlesex Hospital)

Since the recognition of avitaminosis $D$ as the paramount factor in the production of true rickets, certain rare cases have been described, particularly by paediatricians in this country and in the United States, in which administration of the vitamin, even parenterally and in enormous doses, fails to produce that healing of the disease which regularly occurs with such therapy in the vast majority of rickety children.

\section{Theoretical considerations}

After infancy, rickets appears if the calcium, phosphorus and vitamin D requirements of the growing skeleton become insufficient, i.e. with deficient intake ; in the presence of severe calcium drain without compensatory intake ; with non-irradiation of body ergosterol ; when calcium-phosphorus balance is markedly disturbed ; and lastly if absorption fails to occur from the bowel. Thus, the conditions in which rickets can occur may be tabulated as under :

1. Nutritional :

(a) absolute (adverse social circumstances) ;

(b) relative (pregnancy and lactation).

2. Lack of sunshine :

(a) absolute ;

(b) relative (coloured races).

3. Advanced renal disease.

4. Coeliac disease.

But cases are also seen in which none of the above factors seems to operate and the rickets is extremely resistant to vitamin therapy. In such cases the disease remains active until growth has ceased. It is with these vitamin-resistant cases that this paper is mainly concerned. The clinical and radiological picture is that of florid rickets, and the differentiation from the relatively common nutritional type can only be made when the lack of response of the former to therapy is noted. Indeed, it is often a matter of some surprise to the clinician to find that what appears as a simple case of rickets remains stubbornly in statu quo despite the exhibition of vitamin $\mathrm{D}$ in the usual doses. Enormous doses likewise produce little or no effect upon the condition, and it is only when growth 
ceases that the rickets heals. The following cases are illustrative of this rare disease.

\section{Case reports}

Case 1. G. P., a boy aged four years, was admitted in May 1936 because he was walking badly. There was no history of diarrhoea and no symptoms suggestive of renal disease. No other members of the family had suffered from rickets or any difficulty in walking. He was a breast-fed child and had had regular cod-liver oil since being weaned.

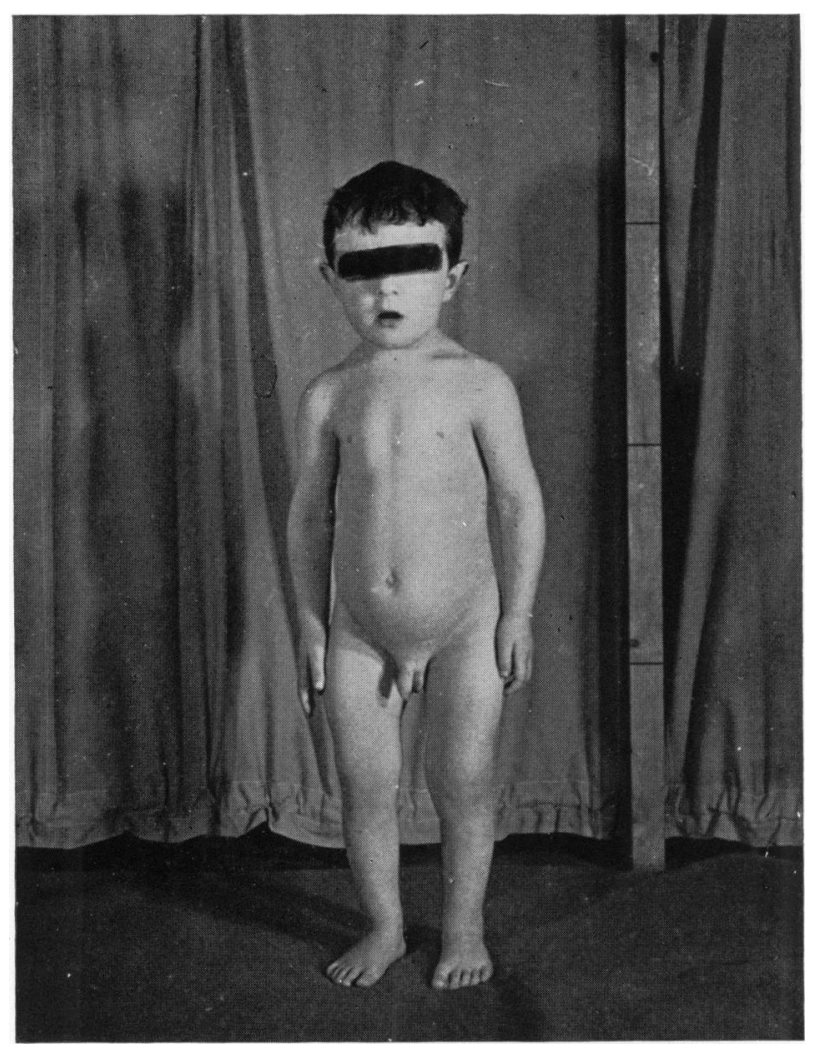

Fig. 1.-Case 1 .

ON EXAMINATION no abnormal physical signs were discovered in the cardiovascular, respiratory or central nervous systems. He was of short stature (fig. 1) and presented enlarged epiphyses at the wrist, a rickety rosary and genu valgum. X-rays (fig. 2) confirmed the clinical diagnosis of rickets. The blood calcium was 10.5 and phosphorus $3.1 \mathrm{mgm}$. per 100 c.c. and blood phosphatase 76 units. The calcium and phosphorus balances were both normal. The total faecal fats were 12.6 per cent. with normal splitting. The glucose tolerance curve and fractional test meal were both normal, as was a complete blood count. Blood analysis gave a normal figure for urea, and uroselectan x-rays of the renal tract were normal, while a Van Slyke urea clearance test showed normal renal 
function. There were no urinary casts. The boy was given calciferol, 4 minims twice daily, and calcium gluconate, 100 grains three times a day, by mouth, without any clinical or radiological improvement; he has continued to take these over a period of nearly three years, during which time he has had in addition three courses of intramuscular vitamin $\mathrm{D}$, each course consisting of four injections of 500,000 units at weekly intervals. He has also had ultraviolet light therapy. He has grown only $3 \frac{3}{8}$ inches in this time, the figures for blood calcium, phosphorus and phosphatase remain unchanged, and finally

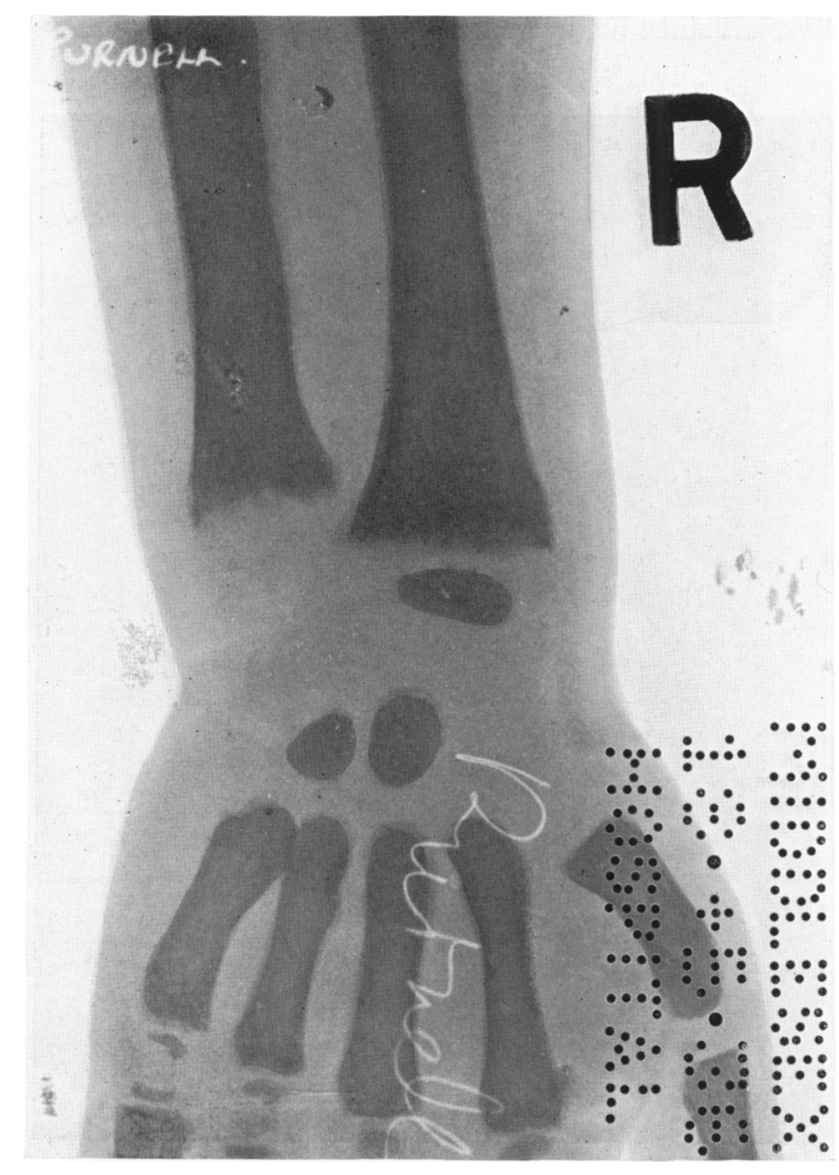

FIG. 2.-Case 1. May, 1936.

there is little, if any, skeletal improvement as judged by clinical and radiological appearances (fig. 3).

Case 2. F. A., a girl aged eight years (sister of J. A., case 3, and daughter of Mrs. A., case 4), was brought to the out-patient department in August 1935 on account of knock-knees which had been present since the age of four years. Feeding had been normal ; there was no history of diarrhoea and no symptoms to suggest renal disease.

ON EXAMINATION there was clinical evidence of rickets, with marked bowing of the femorae and genu valgum (fig. 4). X-ray examination of the skeleton confirmed this diagnosis (fig. 5). The blood calcium and phosphorus were 
both normal, whilst the phosphatase was 71 units. Calcium and phosphorus balances were normal. There was no clinical evidence of renal disease. Figures for blood urea, non-protein nitrogen and cholesterol were normal; urea concentration and urea clearance tests gave normal figures and uroselectan x-ray examination of the renal tract showed no abnormality. The total faecal fats were 27.8 per cent. with normal splitting. Fractional test meal, complete blood count and sugar tolerance curve were all normal and blood Wassermann

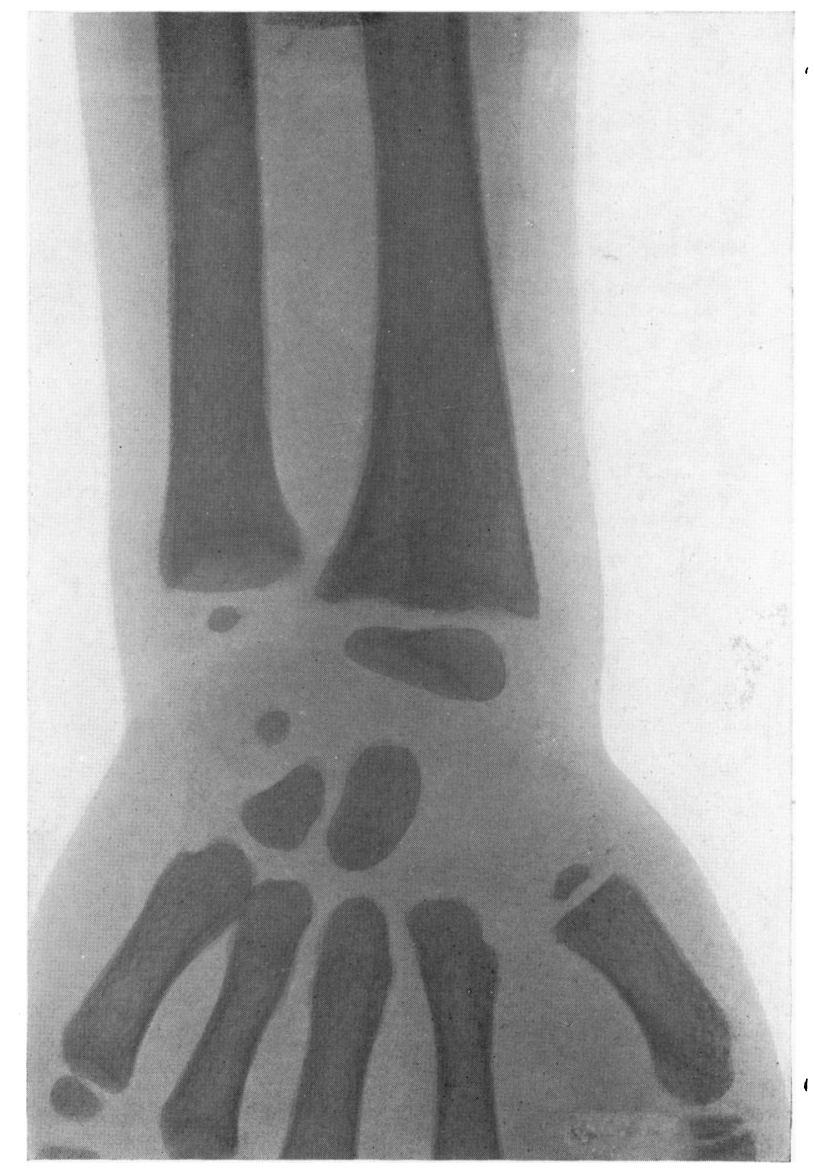

FIG. 3.-Case 1. December, 1938.

reaction was negative. Dentition was normal for her age. She was placed on calciferol, 4 minims twice a day, and calcium gluconate, 120 grains three times a day, by mouth, and in addition has received four courses of intramuscular calciferol over a period of three and a half years, each course consisting of four injections of 500,000 units given at weekly intervals. She has also had ultraviolet light therapy. Blood calcium and phosphorus remained normal, phosphatase fell to 37 units but further x-ray examination failed to reveal any skeletal improvement (fig. 6). She has, however, grown six inches while under treatment.

Case 3. J. A., a girl aged four years (sister of F. A., case 2), was brought 
to the out-patient department by her mother (Mrs. A., case 4) by request for examination, and it was found that she also showed clinical evidence of rickets (fig. 4). X-ray examination of her skeleton confirmed this diagnosis (fig. 7). Blood calcium and phosphorus were normal, whilst phosphatase was 39 units. Calcium and phosphorus balances were normal. There was no history of diarrhoea, no symptoms suggestive of renal disease, and feeding had been normal. Analysis of the faecal fats gave a total of 10.9 per cent. with normal

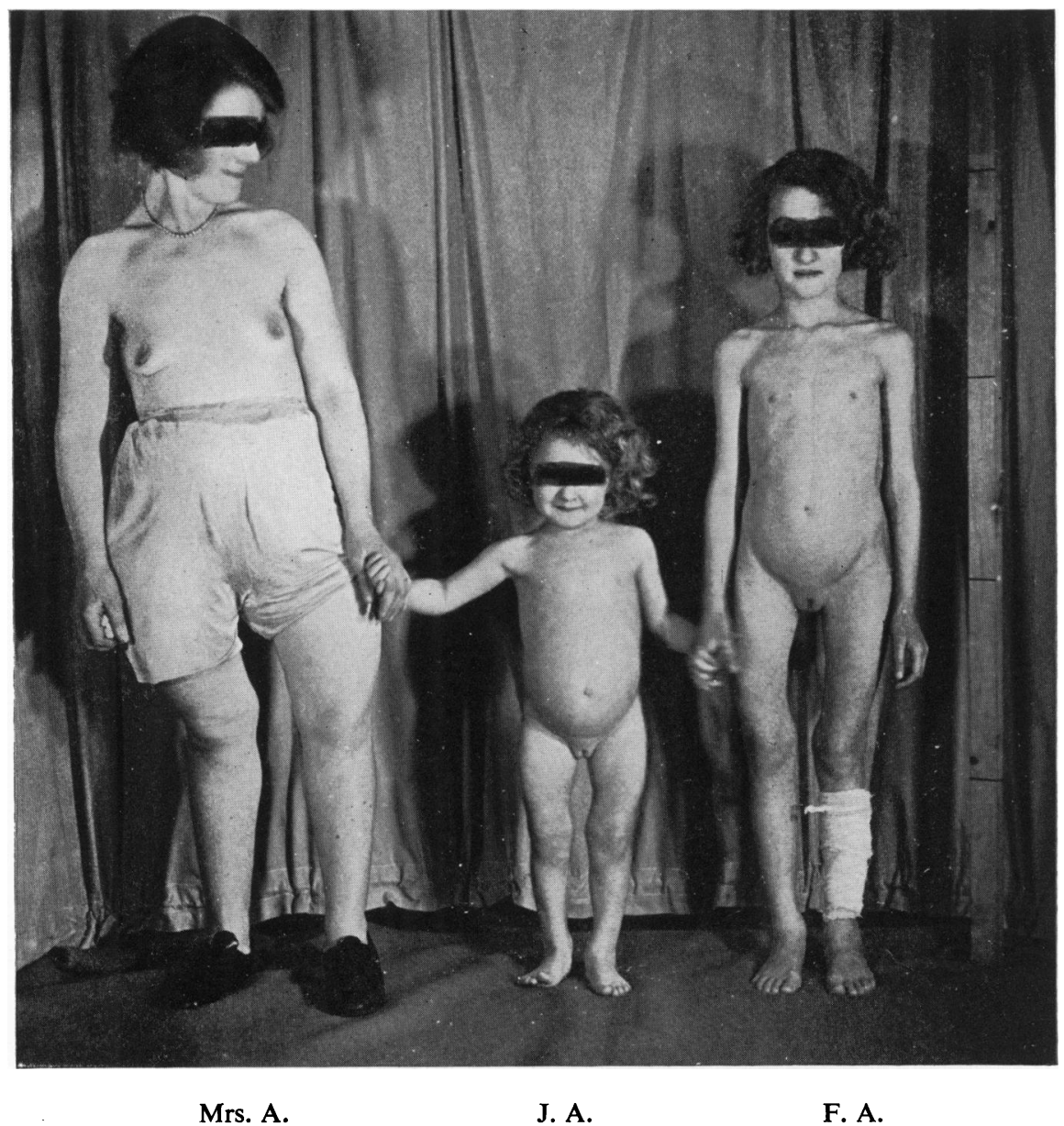

FIG. 4.

splitting. No casts were present in the urine. The blood urea and Van Slyke urea clearance test were normal and uroselectan x-ray examination of the renal tract showed no abnormality. A complete blood count was normal.

She was placed on calciferol, 4 minims twice a day, and calcium gluconate, 120 grains three times a day, by mouth, and was given four courses of intramuscular calciferol over a period of two and a half years, each course consisting of four injections, each of 500,000 units given at weekly intervals. She has also had ultra-violet light therapy. The blood calcium and phosphorus remained normal, while the phosphatase fell to 20 units and further $\mathrm{x}$-ray 


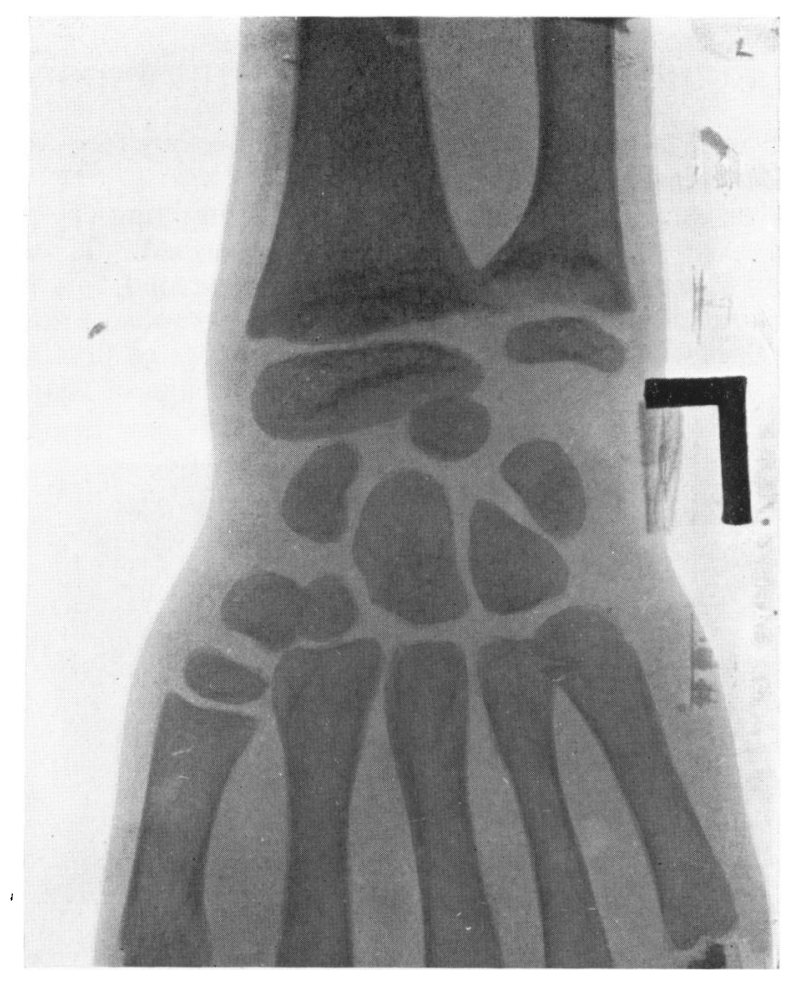

FIG. 5.-Case 2. August, 1935.

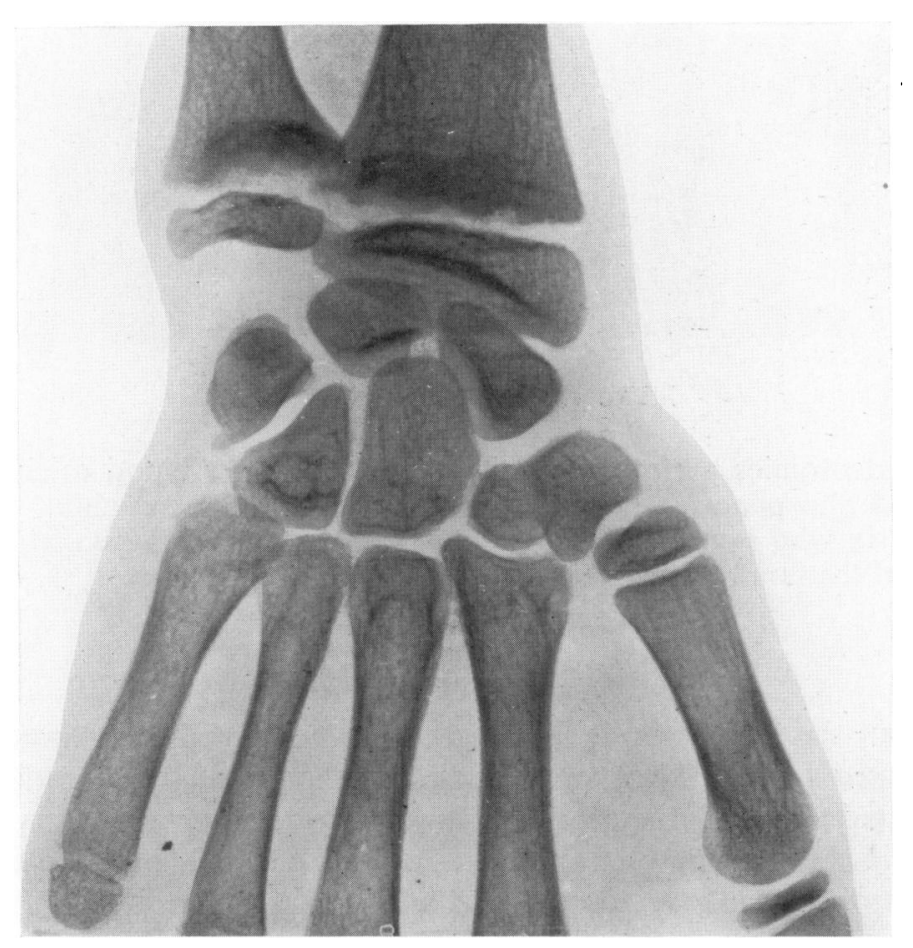

FIG. 6.-Case 2. December, 1938. 
examination showed a tendency to healing of the rickets (fig. 8). During this time her height increased by $3 \frac{1}{2}$ inches.

Case 4. Mrs. A., aged 36, brought her two daughters (F. A., case 2, and J. A., case 3) to the out-patient department as described. It was noticed that she was of small stature and on examination she presented, in addition, bowing of the femorae and tibiae (fig. 4) whilst x-ray photographs of her skeleton confirmed this and presented the radiological appearances of healed rickets. She stated that her legs had become bowed at about the age of four years and she

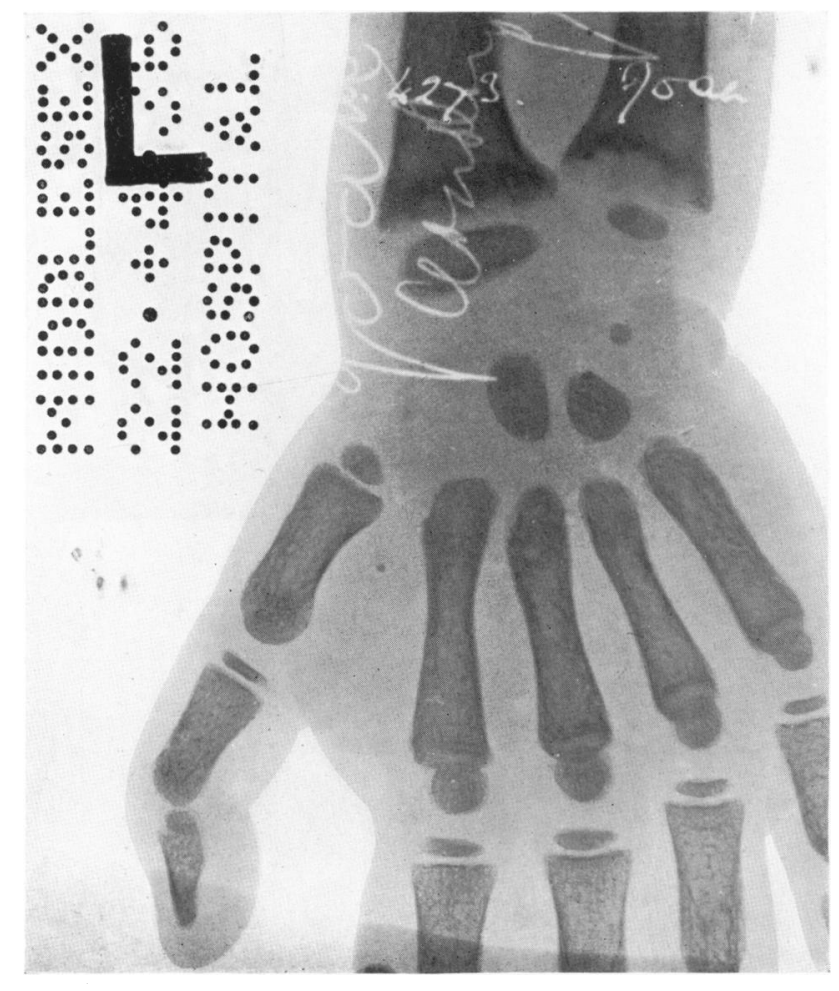

FIg. 7.-Case 3. April, 1936.

had had osteotomies performed at the age of six. Her blood calcium, phosphorus and phosphatase were all normal. She has one other child, also a girl, now aged six who is normal and there is no evidence of rickets in any other members of the family either on the maternal or paternal side.

\section{Commentary}

At about the same time as the above cases came under observation there also presented for treatment two Indian boys. Clinically and radiologically they appeared to be suffering from the same disease, and yet there was a striking difference in their response to the same therapy. It is in order to emphasize this that the following cases are included in this paper. 
Case 5. C. P., a boy aged thirteen years, brother of K. P. (case 6), attended the out-patient department in July 1936 complaining of pains in the knees on walking of some two years' duration. He had been born in India and had come to England in 1932, i.e. two years before the onset of the symptoms. He was a breast-fed baby and since then had been on a strict vegetarian diet, which, however, included plenty of unboiled milk. There was no history of diarrhoea or of any symptoms suggestive of renal disease and there were no serious illnesses in the past history. Apart from his brother, K. P., no other members of the family suffered from any bony disease.

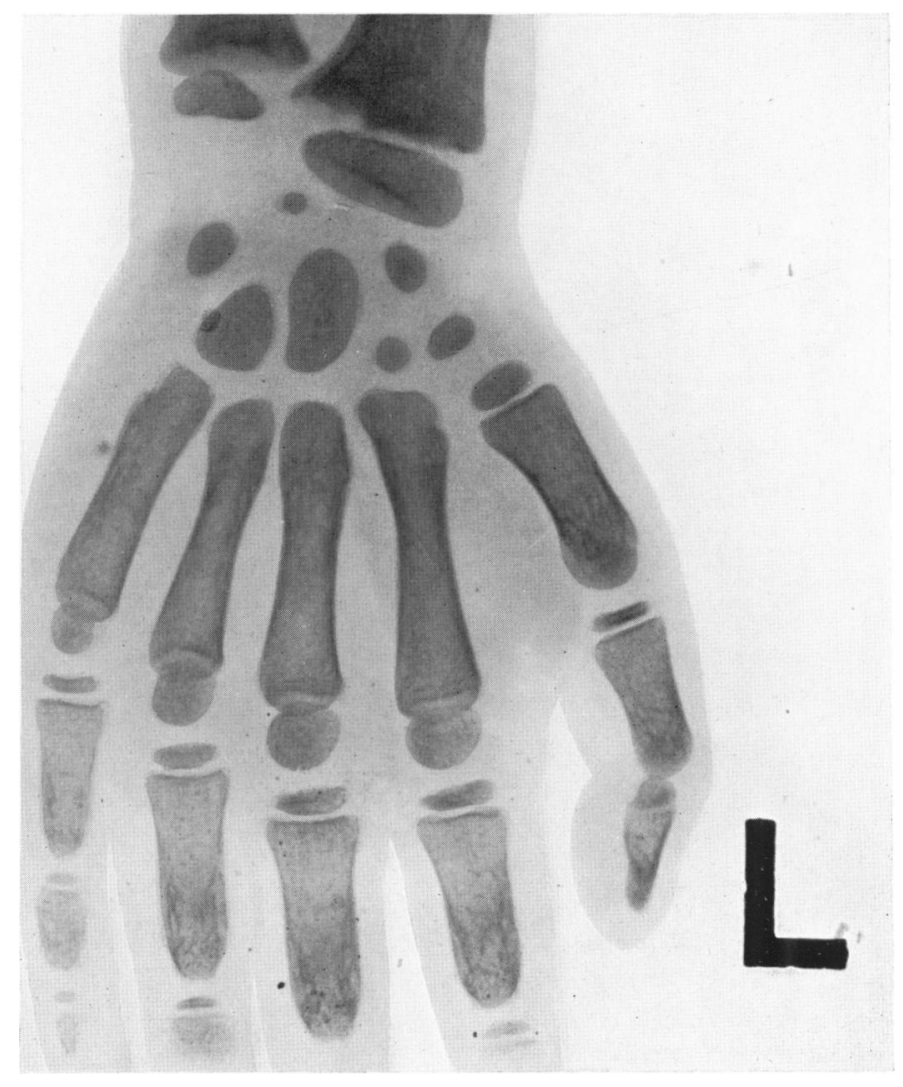

FIG. 8.-Case 3. December, 1938.

ON EXAMINATION the boy was of normal height (fig. 9) and no abnormal physical signs were discovered on examination of the cardiovascular, respiratory or central nervous systems. The blood pressure was $105 / 70 \mathrm{~mm}$. $\mathrm{Hg}$, the optic fundi were normal, and the urine contained no abnormalities. The femorae were bowed laterally, there was marked genu valgum, and the wrist epiphyses were enlarged.

The following renal investigations were performed with normal results : Van Slyke urea clearance test, estimation of blood urea and non-protein nitrogen and uroselectan $\mathrm{x}$-ray of the renal tract. Estimation of the faecal fats was normal. A glucose tolerance curve, fractional test meal and complete blood count were normal. The blood calcium was 7.5 and blood phosphorus 
$4 \cdot 1 \mathrm{mgm}$. per 100 c.c., while the blood phosphatase was 85 units. The calcium balance and phosphorus balance were normal. X-ray examination of the skeleton showed advanced rickets (fig. 10). The skull and pituitary fossa were normal.

Treatment. The boy was given calciferol, 4 minims twice daily and calcium gluconate, 100 grains three times a day, and showed steady improve-

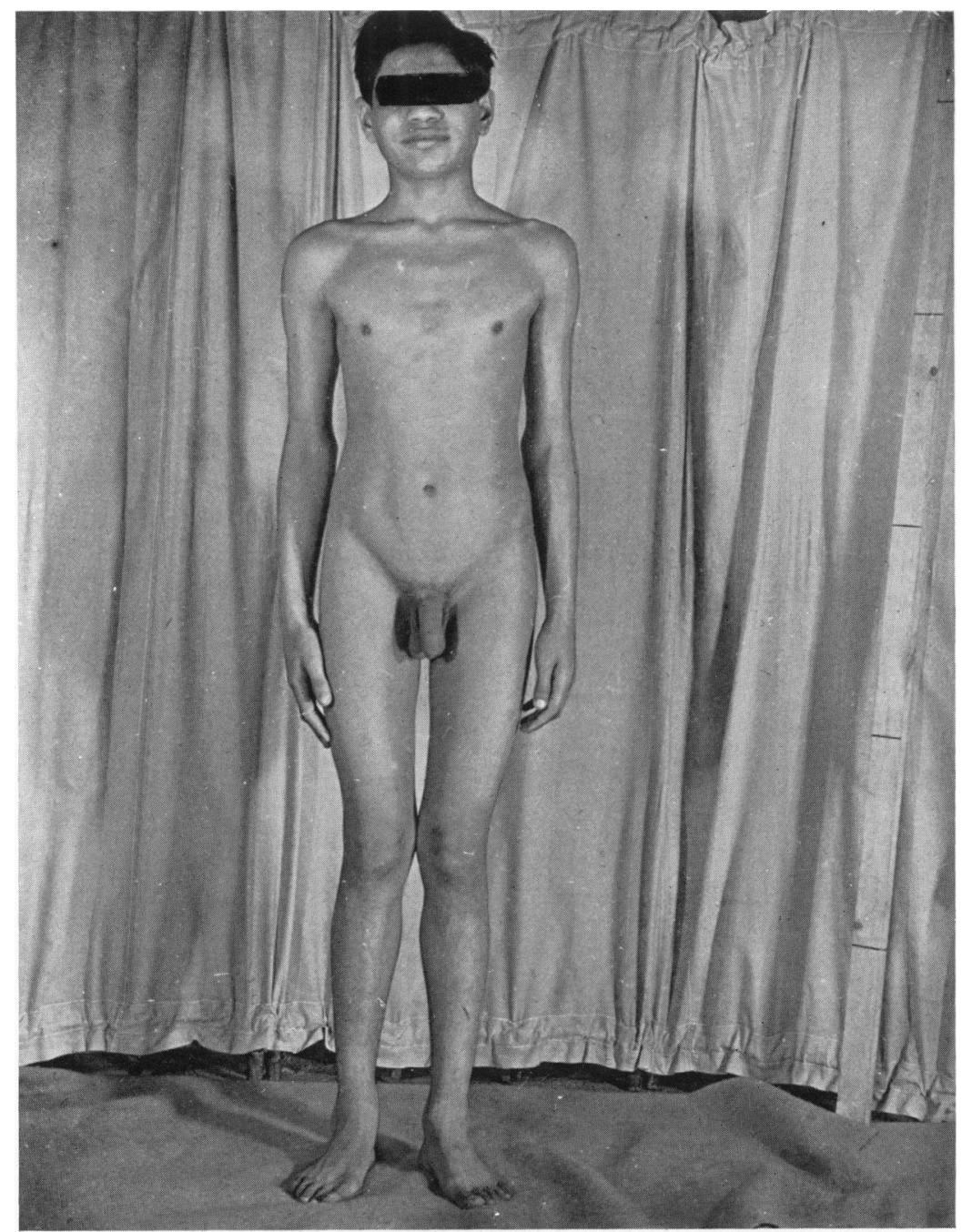

FIG. 9.-Case 5.

ment both clinically and radiologically (fig. 11). The blood calcium rose to $10 \mathrm{mgm}$. per 100 c.c. and the blood phosphatase fell to 47 units.

Case 6. K. P., a boy aged eight years, attended the out-patient department in July 1936 with his brother C. P. (case 5), complaining of difficulty in walking which had been present for one year, i.e. three years after coming to England. He had been born in India, was breast fed and then had been on a strict vege- 


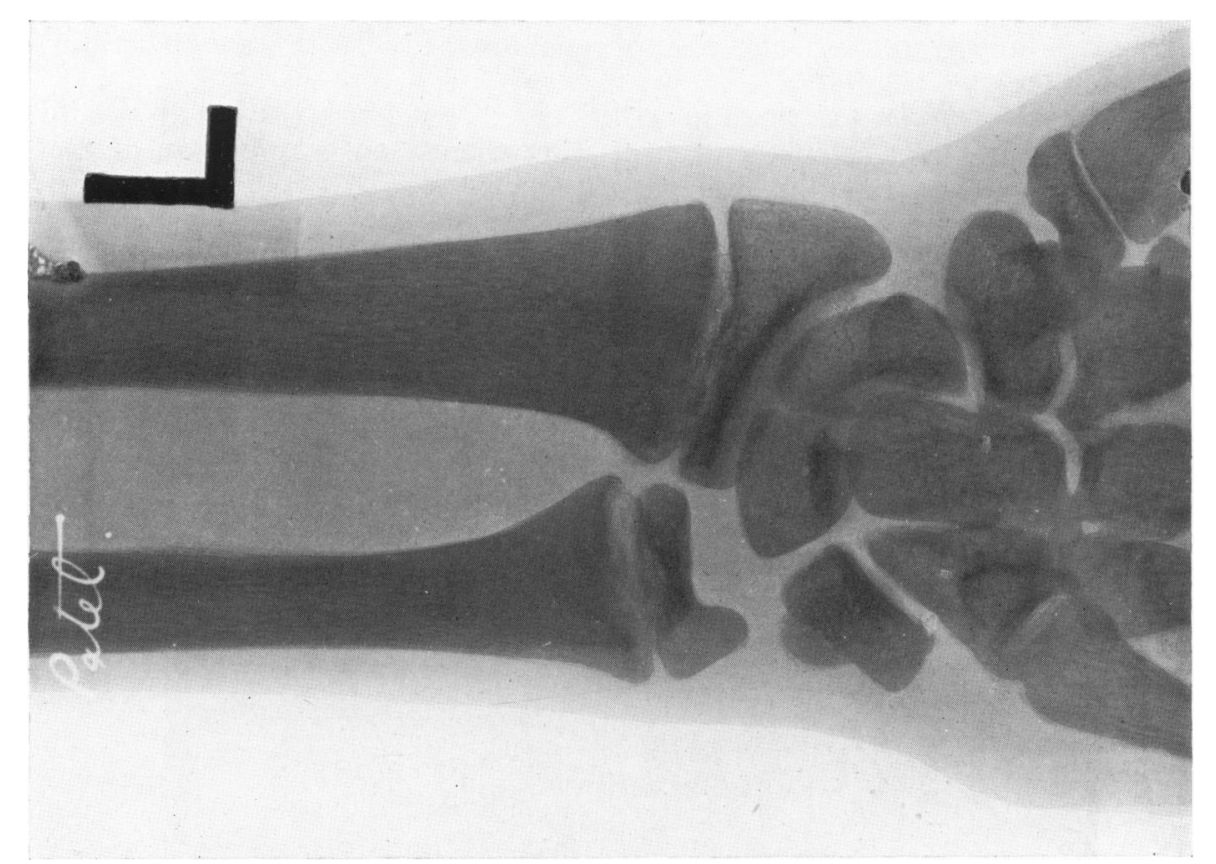

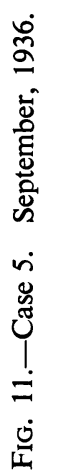

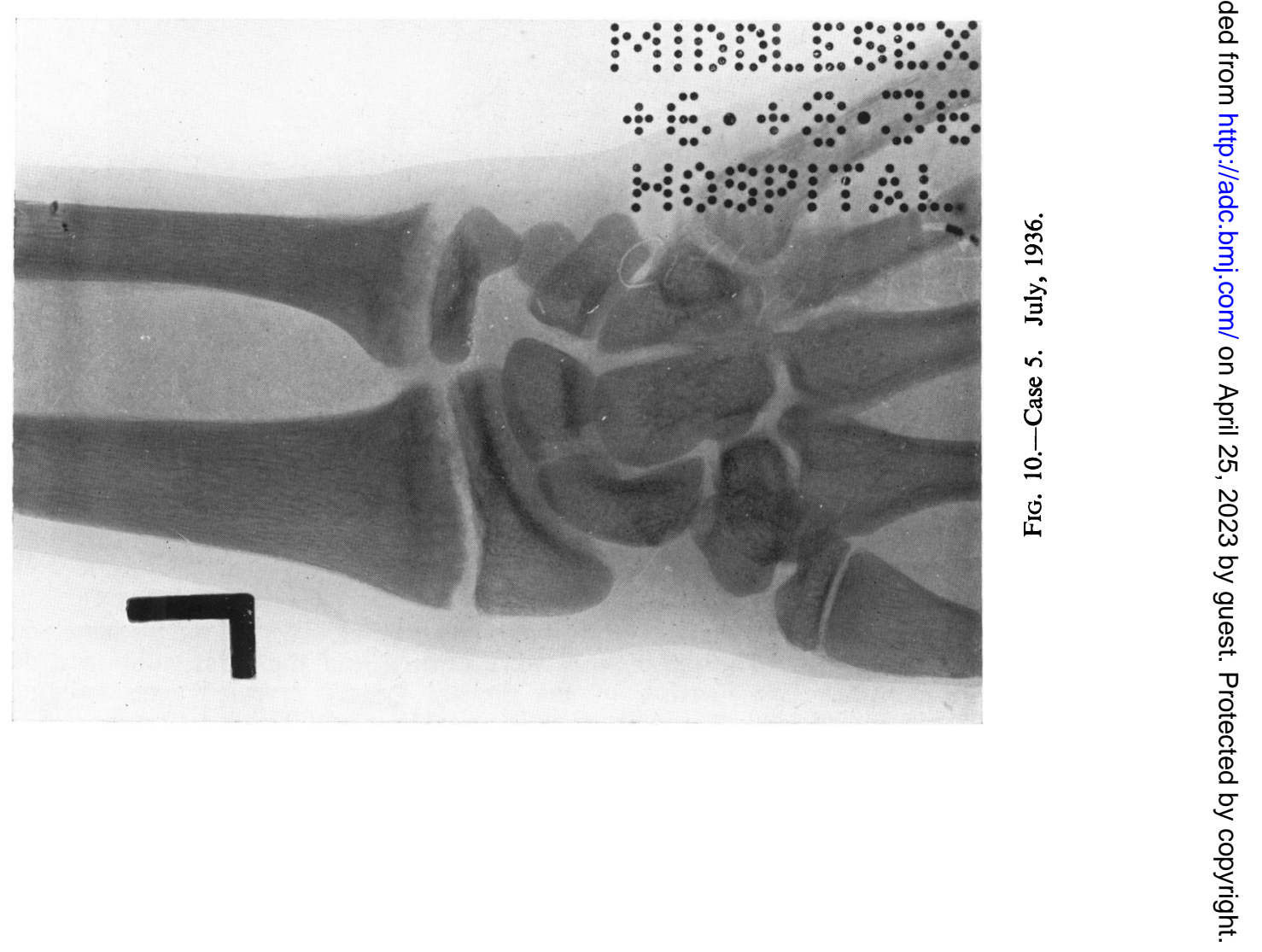


tarian diet, containing plenty of unboiled milk. There was no history of diarrhoea or any symptoms suggestive of renal disease. There were no serious illnesses in the past history.

ON EXAMINATION he was small in stature (fig. 12) and was pitted with smallpox scars. No abnormal physical signs were elicited on examination of the

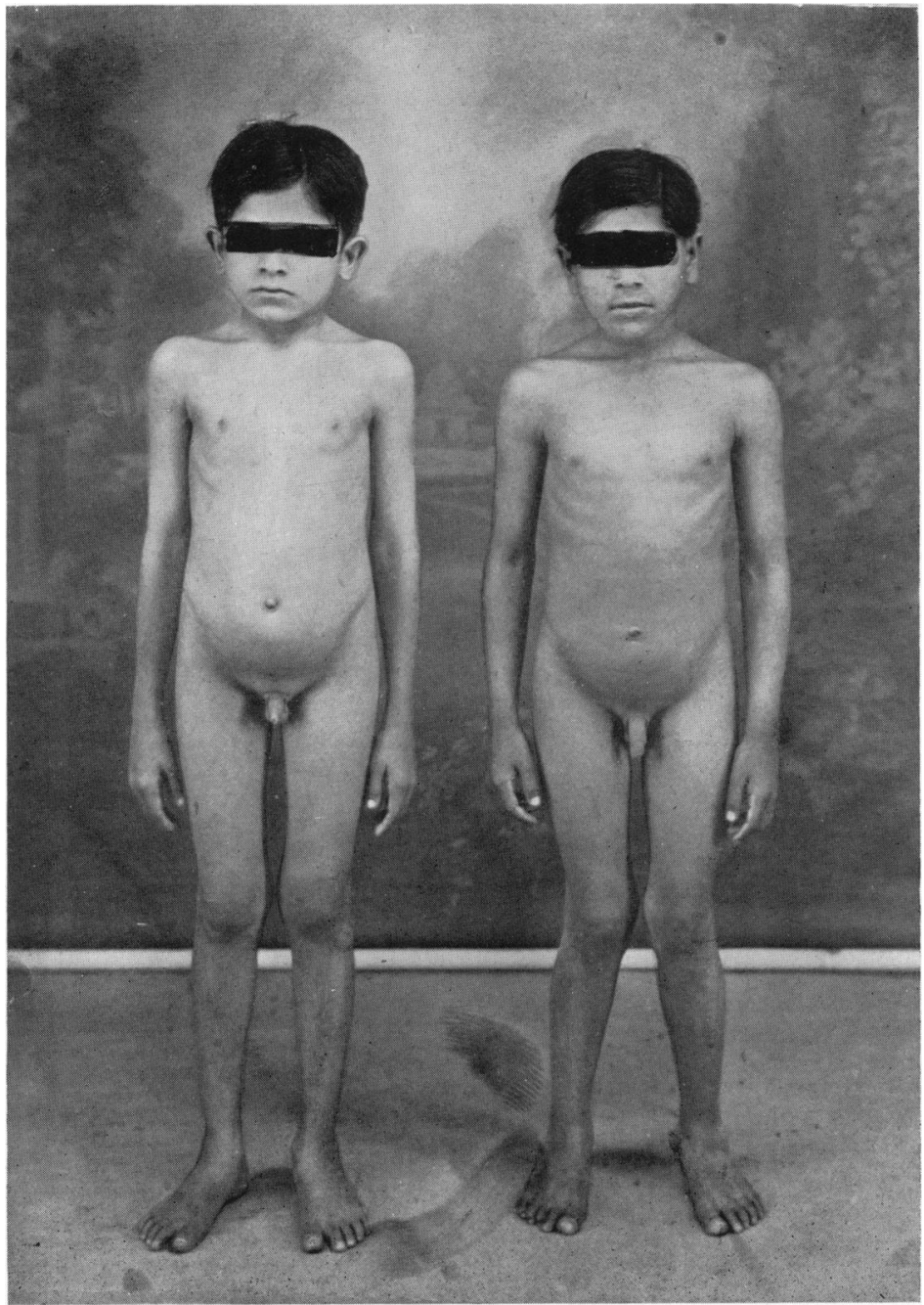

Normal control.

K. P.

FIG. 12.-Case 6.

cardiovascular, respiratory or central nervous systems. The blood pressure was $100 / 60 \mathrm{~mm}$. Hg. The optic fundi were normal and the urine contained no abnormalities. Examination of the skeletal system revealed genu valgum, femorae bowed laterally, enlarged wrist epiphyses and a rickety rosary. The following renal investigations were performed with normal results : Van Slyke urea clearance test, estimation of blood urea and non-protein nitrogen 


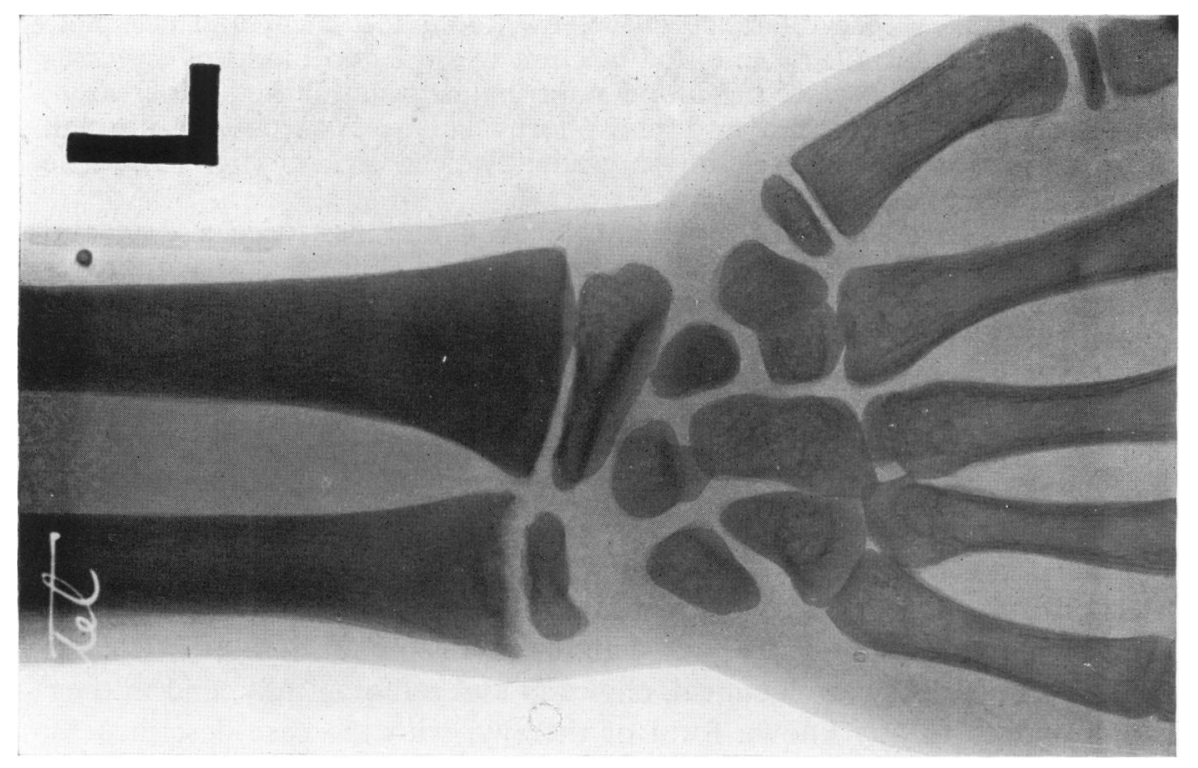

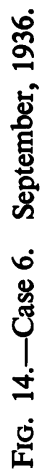
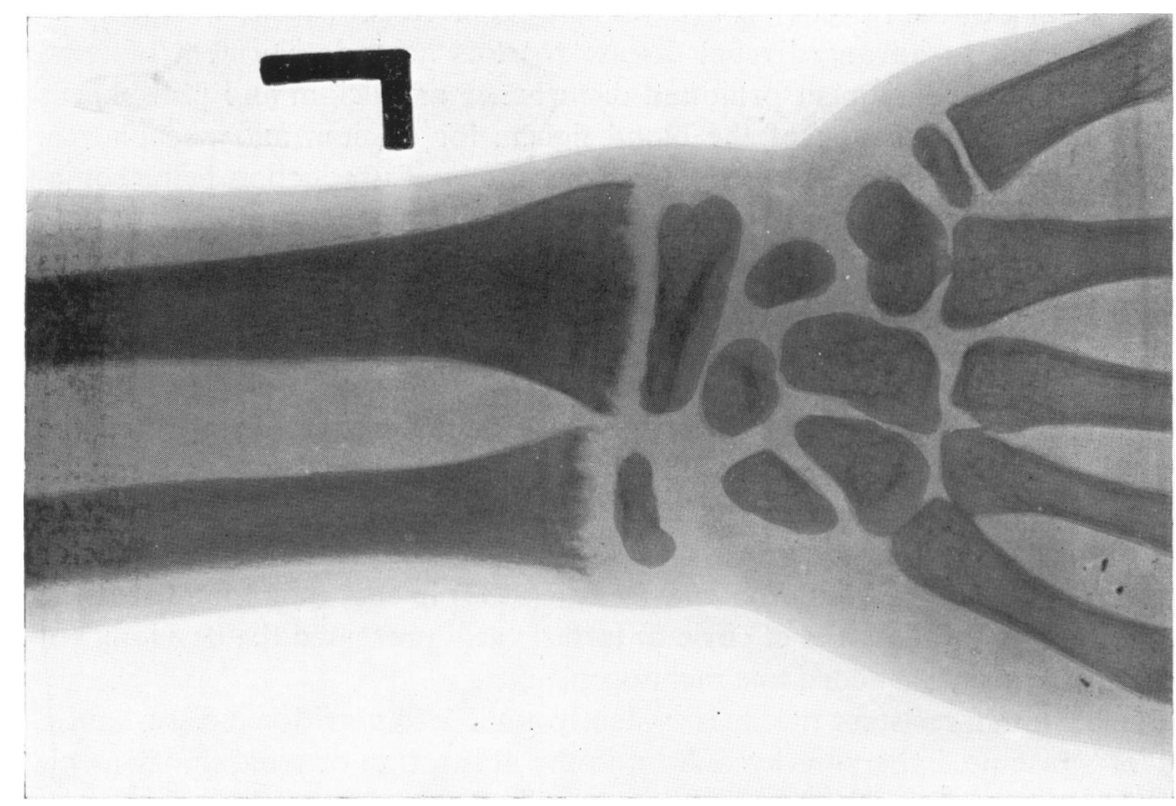

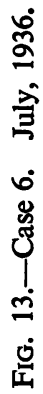


and uroselectan $\mathrm{x}$-ray examination of the renal tract. Estimation of the faecal fats was normal. Sugar tolerance curve, fractional test meal and complete blood count were normal. The blood calcium was 6.2 and blood phosphorus $5.7 \mathrm{mgm}$. per 100 c.c., while the blood phosphatase was markedly increased, being 96 units. The calcium and phosphorus balances were both normal. X-ray examination of the skeleton showed advanced rickets (fig. 13). The skull and pituitary fossa were normal.

TREATMENT. The boy was given calciferol, 4 minims, twice a day, and calcium gluconate, 100 grains, three times a day, and showed steady improvement both clinically and radiologically (fig. 14). The blood calcium rose to $9 \cdot 2 \mathrm{mgm}$. per 100 c.c. and the blood phosphatase fell to 52 units.

Both boys returned to India in February 1937, and their doctor has written to say that their progress has been maintained.

\section{Discussion}

It is difficult to understand the mechanism of production of these cases of vitamin-resistant rickets. There can be no reasonable doubt that they are cases of true rickets, for they are identical, clinically and radiologically, and in their lack of response to any known form of therapy, with the case described by Albright, Butler and Bloomberg (1937), similarly observed and treated over a number of years and in which biopsy gave final proof of the disease. Moncrieff (1935) has seen a similar case in a child aged seventeen months.

In nutritional rickets and in rickets due to lack of sunlight, the response to therapy is invariably rapid and striking (cf. cases 5 and 6). In coeliac disease the etiology of the rickets is fairly well understood and ultra-violet light alone causes healing of the rickets. The cases here reported showed no healing after such therapy. In advanced renal disease there is gross impairment of renal function, with a consequent profound disturbance of calcium and phosphorus metabolism and alteration of the blood figures for calcium and phosphorus. In the growing child rickets ensues, the exact mode of production being somewhat obscure. In the cases of vitamin-resistant rickets here described, not only is renal function normal, but the figures for blood calcium and phosphorus remain within normal limits. The blood phosphatase, on the other hand, is invariably high, as it always is in active rickets, giving some indication of the activity of the rachitic process.

Albright and his co-workers, in their case quoted above, investigated the possibility of calcium drain, due to hyperparathyroidism, with negative results. The normal blood calcium and calcium balance in these cases is sufficient to rule out a primary hyperparathyroid defect. A possible biochemical factor has been suggested by Hamilton and Dewar (1937) in that they found that the addition of the sodium salts of citric or tartaric acid prevented the development of rickets in rats when added to a rachitogenic diet.

Since vitamin-resistant rickets is evidently not due to nutritional disturbance, lack of sunshine, hyperparathyroidism, faulty absorption or renal impairment, and since the condition heals spontaneously when growth ceases, the fault may perhaps be a failure of utilization at the site of bone growth. 


\section{Summary}

Four cases of rickets are described in none of which was there any evidence of malnutrition, lack of sunlight, calcium drain, coeliac or renal disease, and in none of which did any of the known forms of therapy, given over a period of several years, produce evidence of healing. Healing occurs spontaneously when growth ceases. It is suggested that the fault may be a failure of utilization at the site of bone growth.

Thanks are due to Dr. H. E. A. Boldero for permission to record cases 5 and 6, to Dr. Graham Hodgson for the use of the X-ray photographs, to Professor E. C. Dodds for the biochemical investigations and to Dr. J. W. Todd for the photographs of all cases except case 6, which was taken by Dr. Patel.

\section{REFERENCES}

Albright, F., Butler, A. M., and Bloomberg, E. (1937). Amer. J. Dis. Child., 54, 529. Hamilton, B., and Dewar, M. M. (1937). Ibid., 54, 548.

Moncrieff, A. A. (1935). J. Physiol., 85, 26P. 